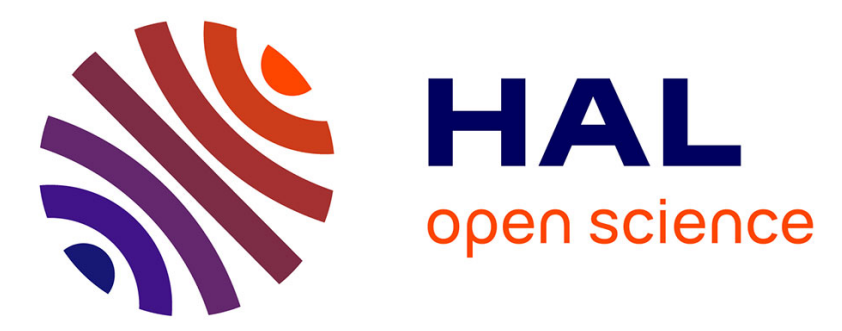

\title{
Evolution of a low-alloy steel / nickel superalloy dissimilar metal weld during post-weld heat treatment
}

Cayo V da Silva Lima, M. Verdier, F. Robaut, J. Ghanbaja, G. Badinier, T.

Marlaud, C. Tassin, Hugo P. van Landeghem

\section{- To cite this version:}

Cayo V da Silva Lima, M. Verdier, F. Robaut, J. Ghanbaja, G. Badinier, et al.. Evolution of a lowalloy steel / nickel superalloy dissimilar metal weld during post-weld heat treatment. Welding in the World, 2021, 10.1007/s40194-021-01146-8 . hal-02382935v2

\section{HAL Id: hal-02382935 \\ https://hal.science/hal-02382935v2}

Submitted on 1 Jun 2021

HAL is a multi-disciplinary open access archive for the deposit and dissemination of scientific research documents, whether they are published or not. The documents may come from teaching and research institutions in France or abroad, or from public or private research centers.
L'archive ouverte pluridisciplinaire HAL, est destinée au dépôt et à la diffusion de documents scientifiques de niveau recherche, publiés ou non, émanant des établissements d'enseignement et de recherche français ou étrangers, des laboratoires publics ou privés. 


\section{Evolution of a low-alloy steel / nickel superalloy dissimilar metal weld during post-weld heat treatment}

C.V. da Silva Lima ${ }^{\mathrm{a}}$, M. Verdier ${ }^{\mathrm{a}}$, F. Robaut ${ }^{\mathrm{a}}$, J. Ghanbaja $^{\mathrm{b}}$, G. Badinier ${ }^{\mathrm{c}}$, T. Marlaud $^{\mathrm{c}}$, C. Tassin $^{\text {a }}$, H.P. Van Landeghem ${ }^{\mathrm{a}}$

${ }^{\text {a }}$ Univ. Grenoble Alpes, CNRS, Grenoble INP, SIMAP, F-38000 Grenoble, France

b Institut Jean Lamour UMR 7198 CNRS, Université de Lorraine, BP 70239, F-54506, Vandœuvre les Nancy, France

${ }^{\mathrm{c}}$ Framatome Lyon, 10 rue Juliette Récamier, F-69456 Lyon Cedex 06, France

Abstract: The design of the dissimilar metal weld investigated here is aimed at applications in the steam generator of a sodium-cooled nuclear reactor, with a multi-decade lifespan in demanding operational conditions. It consists in a narrow-gap joint between $2.25 \mathrm{Cr}-1 \mathrm{Mo}$ lowalloy steel and an austenitic alloy using a nickel-based alloy 82 as filler material. This study focuses on understanding the microstructural and micromechanical evolution in the near fusion boundary region between the low-alloy steel and the nickel alloy filler metal during post-weld heat treatment, using notably electron probe microanalysis and nano-indentation. The difference in matrix phase and chemical composition between the two alloys leads to a large difference in chemical potential for carbon, which is mobile at the post-weld heat treatment temperature. A number of fine-scale characterization techniques were used to assess the gradient of composition, hardness and microstructures across the fusion boundary, both as welded and after post-weld heat treatment. This complete analysis permits to highlight and understand the main microstructural and micromechanical changes occurring during post-weld heat treatment and opens the way to their long term study in service conditions.

Keywords: DMW; GTAW; PWHT; EPMA; nano-indentation; microstructure

\section{Introduction}

Dissimilar metal welds (DMWs) are a common occurrence in power plants where the need to join different alloys or alloy grades is frequent due to elaborate piping design [1]. Meeting stringent safety requirements over the long life span of the facilities while minimizing cost requires using optimal alloys for the target components. The case studied here is that of a narrow-gap (NG) DMW prototype that would join the steam generator hot collector to the steam circuit in a fourth generation, sodium-cooled nuclear reactor. The pipes of this circuit are planned to be manufactured out of 11CrMo9-10 (1.7383), a 2.25Cr-1Mo low alloy steel (LAS) for high-pressure applications with excellent creep resistance. Such components will be arc welded to the steam generator made of austenitic alloy $800 \mathrm{H}$ (1.4958) using nickel-based alloy

${ }^{1}$ Corresponding author at SIMaP, 1130 rue de la piscine, BP 75, 38402 Saint Martin d'Hères. E-mail: hugo.van-landeghem@grenoble-inp.fr 
82 (2.4806) as filler material. The resulting junction belongs to the broader class of ferritic/austenitic DMWs. The fusion boundary of particular interest here is the one between the LAS (ferritic) and the filler metal (austenitic), where the large mismatch in properties plays a critical part in the performance of the weld [2].

Alloy 82 is a filler metal used in joint design for nuclear power plants, including pressurized water reactors (PWRs) [3] and sodium-cooled fast reactors (SFRs) [4]. In PWRs, alloy 82 was progressively replaced with alloy 52 [5], which displays an enhanced resistance to primary water stress corrosion cracking (SCC) due to its higher chromium content [6]. However, this higher chromium content leads to a more pronounced carbon transfer from the LAS to the weld [7] and to a greater susceptibility to embrittlement by short and/or long range ordering [8,9]. The steam environment in SFRs does not cause SCC and their higher operation temperature exacerbates carbon transport and ordering embrittlement. Thus, alloy 82 remains the more adapted filler metal for future SFR DMWs.

NG gas tungsten arc welding (GTAW) is a joining process used notably for DMW that renders superfluous the use of buttering layers on the LAS nozzle. It presents a number of advantages over previous processes in terms of both cost and performance. However, it has been shown that this change in weld joint design can lead to a different response to PWHT [10]. For the widespread combination of SA508 and 316L joined using alloy 52, PWHT following NGGTAW does not improve [11] and can even worsen [10] the fracture resistance of the zone near the fusion boundary between SA508 and alloy 52. This finding highlights the importance of understanding the effects of PWHT on the microstructure and its associated properties.

The available literature regarding the PWHT of DMWs between 2.25Cr-1Mo LAS and austenitic alloys with alloy 82 as a filler metal is scarce. In addition, the PWHTs that were covered vary in both temperature and duration from one study to another, from $700^{\circ} \mathrm{C}$ for $1 \mathrm{~h}[12]$ to $3 \mathrm{~h}[13]$, to $630^{\circ} \mathrm{C}$ for $7 \mathrm{~h}$ [14]. It is also known that in such joints, the key part is the direct vicinity of the ferritic/austenitic fusion boundary, within a few tens of microns [15]. The purpose of the present paper is thus to investigate the local microstructural and mechanical changes induced by a $2 \mathrm{~h}$ PWHT at $700^{\circ} \mathrm{C}$, in line with welding guidelines. This study is a prerequisite to the investigation of the long term evolution of those joints at their operational temperature $\left(\approx 530^{\circ} \mathrm{C}\right)$. A thorough, fine-scale characterization, involving multiple techniques, of this region in as-welded and PWHT samples is presented in the following to highlight the evolution of the microstructure, the composition gradients and the resulting mechanical properties. The results are then discussed in terms of the chosen PWHT conditions to assess whether they could be altered to yield a more optimal microstructure of the near-fusion boundary zone. 


\section{Experimental}

\subsection{Base materials and processing}

The materials involved in this study are a 11CrMo9-10 LAS forged-plate, an alloy $800 \mathrm{H}$ hotrolled plate and, as filler metal, a $1.2 \mathrm{~mm}$ diameter alloy 82 solid wire. Their compositions are given in Table 1.

A DMW mock-up was made of two plates of parent metal having the same dimensions: $500 \times 150 \times 25 \mathrm{~mm}^{3}$, assembled by a multi-pass butt joint. To limit deformations during welding, the assembly was clamped using three hangers. Welding was performed in flat position $(1 \mathrm{G})$ with a hot-wire GTAW process in narrow groove configuration (1 pass per layer) and using Arcal 37 (70\% He 30\% Ar) as shielding gas. The main welding parameters are:

- GTAW hot-wire - pulled passes,

- No preheating or post-weld "bake-out",

- maximum interpass temperature: $180^{\circ} \mathrm{C}$,

- welding speed: $1.66 \mathrm{~cm} . \mathrm{s}^{-1}$,

- filler feed rate: $\approx 2.33 \mathrm{~cm} . \mathrm{s}^{-1}$,

- fixed welding voltage: $12 \mathrm{~V}$,

- direct and pulsed welding current, $160 \mathrm{~A}$ average.

The joint was then PWHT at $700^{\circ} \mathrm{C}$ for $2 \mathrm{~h}$. The PWHT conditions were chosen in agreement with recommendations from guidelines for welding creep strength-enhanced ferritic alloys on heavy wall weldments, which are $2 \mathrm{~h}$ at $\approx 730^{\circ} \mathrm{C}[16]$ and $2-4 \mathrm{~h}$ between $670^{\circ} \mathrm{C}$ and $720^{\circ} \mathrm{C} \mathrm{[17],}$ respectively, for 11CrMo9-10 LAS.

After welding, the root passes and the finishing passes were removed by machining, in order to have a remaining thickness of $25 \mathrm{~mm}$ welded with the same welding parameters, as illustrated by the metallography of the joint in Fig. 1.

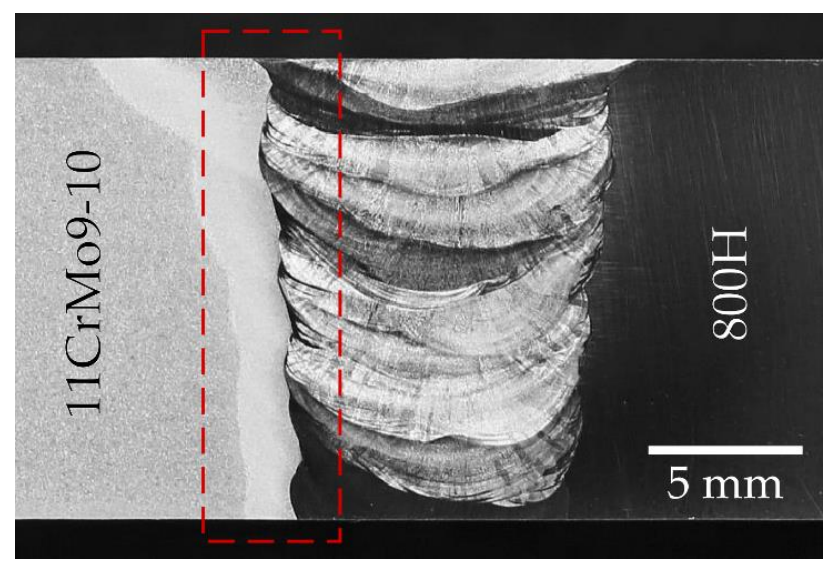

Fig. 1 Macrograph of the studied DMW between 10CrMo9-10 low-alloy steel and alloy 800H, joined using alloy 82 wire as filler metal. The austenite/ferrite fusion boundary is highlighted in the red dashed box

\begin{tabular}{|l|l|l|l|l|l|l|l|l|l|l|l|l|l|l|l|l|}
\hline Alloy & $\mathrm{C}$ & $\mathrm{Cr}$ & $\mathrm{Ni}$ & $\mathrm{Mn}$ & $\mathrm{Si}$ & $\mathrm{Fe}$ & $\mathrm{Mo}$ & $\mathrm{S}$ & $\mathrm{P}$ & $\mathrm{Cu}$ & $\mathrm{Al}$ & $\mathrm{V}$ & $\mathrm{Co}$ & $\mathrm{Ti}$ & $\mathrm{Nb}$ & $\mathrm{Ta}$ \\
\hline 11CrMo9-10 & 0.12 & 2.18 & 0.15 & 0.45 & 0.23 & Bal. & 0.94 & 0.005 & 0.010 & 0.10 & 0.024 & 0.01 & N/A & N/A & N/A & N/A \\
\hline $800 \mathrm{H}$ & 0.07 & 20.58 & 30.31 & 0.60 & 0.52 & Bal. & N/A & 0.002 & 0.011 & 0.07 & 0.25 & N/A & 0.11 & 0.33 & 0.01 & N/A \\
\hline 82 & 0.01 & 20.6 & Bal. & 3.2 & 0.02 & 0.2 & N/A & 0.002 & 0.002 & 0.01 & N/A & N/A & 0.01 & 0.33 & 2.70 & 0.01 \\
\hline
\end{tabular}

Table 1 Chemical compositions (wt. \%) of alloy $800 \mathrm{H}, 11 \mathrm{CrMo} 9-10$ low-alloy steel and alloy 82 used in this study $3 / 23$ 


\subsection{Sample preparation}

Samples prepared for metallographic observations were first cold mounted in an epoxy resin before being ground on $\mathrm{SiC}$ paper down to $\mathrm{P} 2400$ grit. They were then polished using diamond suspensions down to $1 \mu \mathrm{m}$. In order to reveal the microstructure of both 11CrMo9-10 LAS and alloy 82, the samples were dual etched. First, the LAS side was etched using Nital $3 \%$ (3\% $\mathrm{HNO}_{3}$ in methanol) for 20 to $90 \mathrm{~s}$. Then, the weld side, unaffected by the previous step, was electro-etched in a chromic acid solution $\left(10 \% \mathrm{Cr}_{2} \mathrm{O}_{3}\right.$ in water) under a potential of $3 \mathrm{~V}$, resulting in a current density of about $0.5 \mathrm{~A} . \mathrm{cm}^{-2}$ for $3 \mathrm{~s}$. After etching, the samples were observed using an Olympus BX60M light microscope and a Zeiss Gemini scanning electron microscope (SEM) operated at $10 \mathrm{kV}$.

To ensure that the data from the various small-scale characterization techniques could be correlated in a straightforward manner, a number of region of interests (ROIs) were identified and marked on the etched samples. The marking was performed using micro-hardness indents with a $200 \mathrm{~g}$ load.

Given the surface requirements for EPMA and nano-indentation, the samples were appropriately ground again to remove all traces of etching before being polished using diamond suspensions down to $1 \mu \mathrm{m}$. Just before being loaded into the EPMA, the samples and the carbon analysis standards went through a final polishing step using Strüers OP-A suspension followed by thorough rinses with water then ethanol.

\subsection{Electron probe micro-analysis (EPMA)}

The composition profiles were measured in the ROIs with a Cameca SX50 microprobe whose automation was performed with SAMx software. Carbon was analyzed with a tungsten/silicon multilayer monochromator ( $2 \mathrm{~d}$ spacing $=9.5 \mathrm{~nm}$-crystal PC2-) at an accelerating voltage of $13 \mathrm{kV}$ with a $900 \mathrm{nA}$ beam current for improved counting statistics. A liquid nitrogen cold trap and a low-pressure jet of oxygen onto the sample were used to minimize carbon contamination. According to ISO standard 16592:2012, the carbon analysis procedure was based on the evaluation of a calibration curve for the carbon $\mathrm{K} \alpha$ line intensity as a function of carbon content in the range of $0-1 \mathrm{wt} . \%$. This regression curve is a straight line given by:

$$
c t s=A \times w_{C}+B
$$

where $c t s$ is the count number at the intensity peak maximum, $w_{C}$ is carbon weight content, and $\mathrm{A}$ and $\mathrm{B}$ are fit coefficients. In this procedure, background intensity is not measured. The set of homogeneous standards used to determine the calibration curve, consisted of pure iron and fully martensitic steels with, respectively, $0.2 \mathrm{wt} . \% \mathrm{C}$ (20NiCrMo2), $0.42 \mathrm{wt} \% \mathrm{C}$ (42CrMo4), 0.98 wt.\% C (100Cr6), and 0.99 wt.\% C (100Cr6) [18]. Carbon content in the investigated samples was then computed from the regression curve coefficients $\mathrm{A}$ and $\mathrm{B}$.

$\mathrm{Cr}, \mathrm{Mn}$ and $\mathrm{Ni}$ contents were measured at $13 \mathrm{kV}$ and $100 \mathrm{nA}$, with $\mathrm{LiF}$ monochromators $(2 \mathrm{~d}$ spacing $=0.4 \mathrm{~nm})$. The classic quantitative analytical procedure was taken into account using the ratio of measured intensities of the Ka line from the specimen and the pure metallic standards. Background intensity was measured and deducted from the peak intensity. The 
smallest step size in the profiles was $4 \mu \mathrm{m}$ as it is the minimum step size known to completely prevent contamination artefacts from one point to the next in a profile.

\subsection{Nanoindentation}

Local mechanical properties were measured using a commercial machine (MTS-XP) along two regularly spaced grids, as shown in Fig. 2. Those two grids consisted of a coarse matrix (typically $30 \times 2$ indents at $450 \mathrm{~nm}$ depth, separated by $20 \mu \mathrm{m}$ ) along the EPMA profile and a fine matrix (typically $30 \times 6$ indents at $120 \mathrm{~nm}$ depth, separated by $2.5 \mu \mathrm{m}$ in $\mathrm{X}$ and $5 \mu \mathrm{m}$ in $\mathrm{Y}$ ) straddling the fusion boundary in between the rows of the coarse matrix. Additionally, two reference matrices for both weld metal and LAS ( $3 \times 2$ indents, $450 \mathrm{~nm}$ depth) were made more than $1 \mathrm{~mm}$ away to obtain average values of the properties far from the fusion boundary. Tests were carried out using a Berkovich indenter to a predefined depth with a constant strain rate of $10^{-2} \mathrm{~s}^{-1}$, with a continuous stiffness measurement (superimposed $2 \mathrm{~nm}$ displacement amplitude at $80 \mathrm{~Hz}$ ). Standard analysis using Oliver and Pharr method are used to obtain both Young modulus (E) and hardness $(\mathrm{H})$ at specified depth. The sample preparation used for EPMA provides the surface roughness required to conduct measurements at shallow depths $(100 \mathrm{~nm}$ for the smallest one).

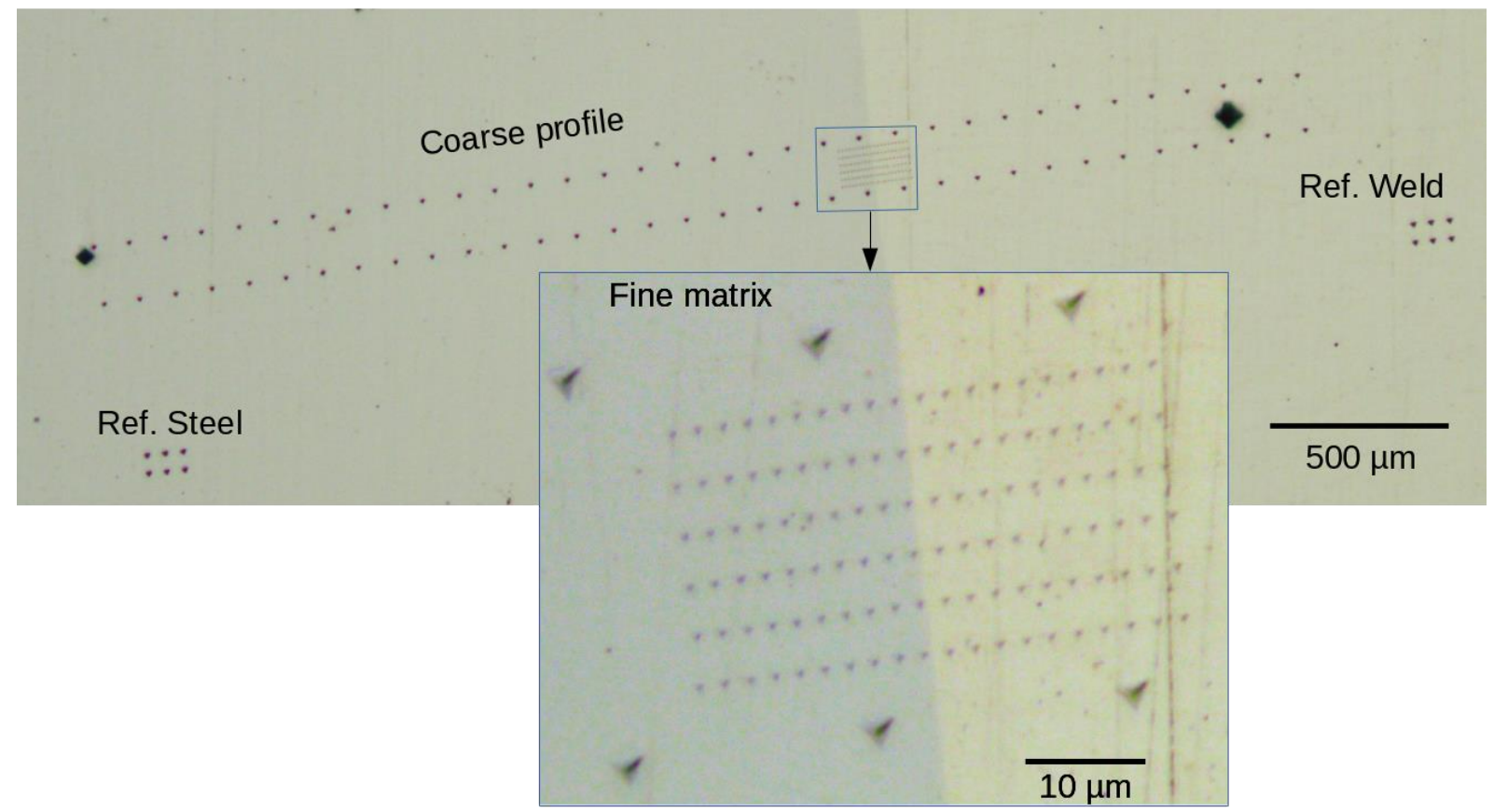

Fig. 2 Light micrographs showing the typical arrangement of nano-indents across the fusion boundary in two matrices, coarse and fine. The Vickers micro-indents used to mark the region of interest are also visible on both sides of the boundary

\subsection{Transmission Electron Microscopy (TEM)}

Lamellae for TEM observations were lifted out from the samples using an FEI Helios NanoLab 650 dual beam microscope. The lamellae were then further thinned in a Gatan PIPS II operated at $500 \mathrm{~V}$, for a total of $2 \mathrm{~min}$ on each side, in $30 \mathrm{~s}$ steps. Before the observations, the lamellae were cleaned in a Gatan Solarus plasma cleaner for $4 \mathrm{~min}$ in an $\mathrm{Ar} / \mathrm{H}_{2}$ mixture followed by for 4 min in $\mathrm{O}_{2} / \mathrm{H}_{2}$. The specimens were observed in a JEOL 2100F equipped with a Centurio 
energy dispersive spectroscopy (EDS) detector and in a JEOL AccelARM both operated at $200 \mathrm{kV}$. EDS analyses were carried out using JEOL Analysis Station software with drift correction enabled.

\section{Results}

\subsection{Composition profiles}

The typical composition profiles for carbon and the main substitutional elements in the aswelded condition can be seen in Fig. 3. Regarding substitutional elements, the composition on the steel side is constant and corresponds to the bulk content of $11 \mathrm{CrMo} 9-10$. Past the fusion boundary, there exists a composition gradient with increasing $\mathrm{Cr}, \mathrm{Mn}$ and $\mathrm{Ni}$ content. This gradient zone is known as the partially mixed zone (PMZ) and is present in any DMW [19]. Further in the weld, those content values stabilize in the fully mixed zone (FMZ) but it should be noted that they never reach the bulk composition of alloy 82. The limit between the PMZ and the FMZ is taken here as the point where the nickel composition reaches $98 \%$ of its plateau value in the weld. Based on this stabilized composition far from the fusion boundary, a dilution coefficient can be calculated at about $4 \%$ of LAS. This low dilution coefficient reveals that the metal filler feed rate was high with respect to the heat input of the process [20]. The size of the partially mixed zone varies along the fusion boundary, bead to bead and within beads. However, the general shapes of the substitutional gradients are the same across all samples and locations, and are not affected in a detectable manner by the PWHT used here. Thus, ROIs in as-welded and PWHT samples were labeled based on the size of their partially mixed zone, either large (L) or small (S) as detailed in Table 2. Table 2 also lists the size of the white layer of the different ROIs, a microstructural feature detailed in section 3.2, where the location of the ROIs in the microstructure can also be found.

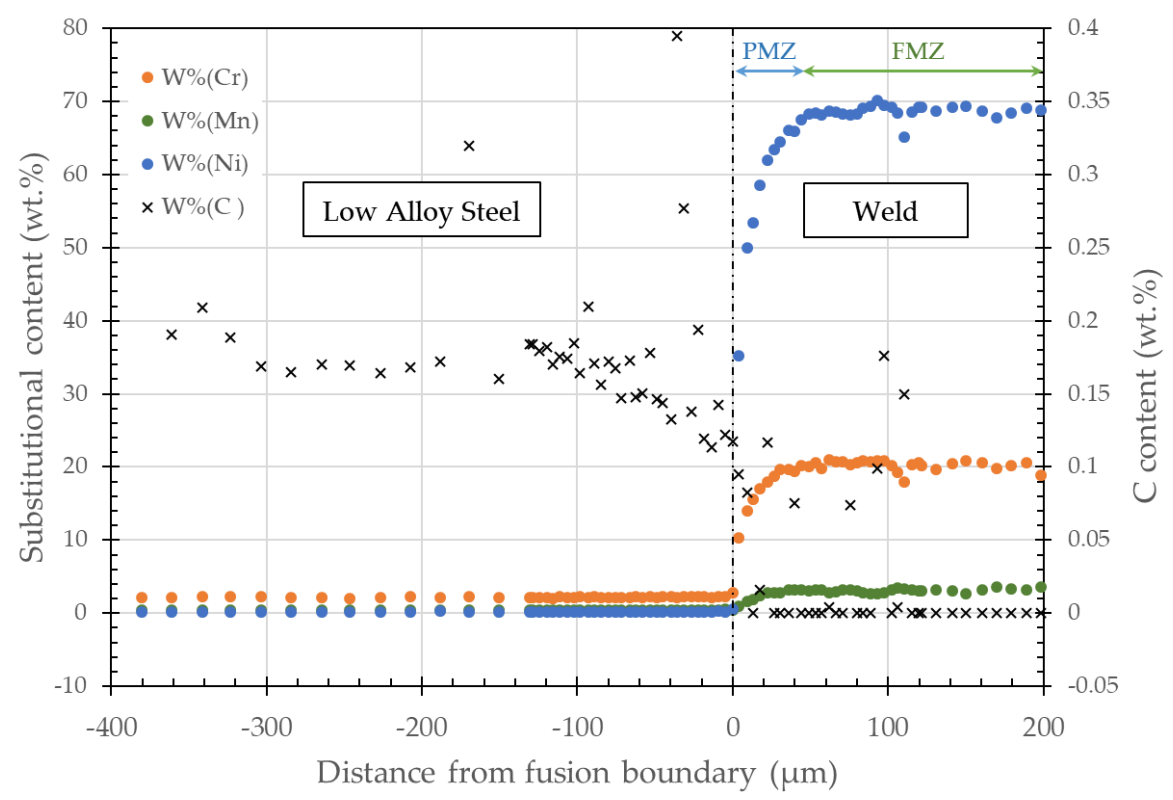

Fig. 3 Composition profile across the fusion boundary of region L in as-welded sample AW1, measured using EPMA. The overall shape of the substitutional profile is representative of the present dissimilar metal welds, although the length of the partially mixed zone varies along the fusion boundary. A slightly decarburized area, about $100 \mu \mathrm{m}$ long, can be seen on the low-alloy steel side and is a typical feature as well 


\subsubsection{As-welded}

Fig. 4 shows a collection of carbon profiles recorded at different ROIs in as-welded samples AW1 and AW2. In the as-welded condition, it can be seen that all carbon profiles are very similar. Up until $100 \mu \mathrm{m}$ before the fusion boundary, the concentrations found on the LAS side correspond roughly to the nominal bulk composition. In the $100 \mu \mathrm{m}$ before the fusion boundary, a decreasing gradient in carbon concentration indicates carbon transport from the body centered cubic (BCC) LAS side to the FCC weld side. In this same region, the profile looks very chaotic. This aspect can be attributed to the tempering of the LAS caused by the heat input from the welding process. This tempering leads to the formation of carbides, which in turn, cause large fluctuations of the local carbon concentration depending on whether or not they are caught by the EPMA probe. Right against the fusion boundary on the weld side, small carbon peaks can be distinguished in cases AW1-S and AW2-S. Further in the weld, carbon concentration drops back down to zero with sudden, large fluctuations ascribed to the presence of coarse, micronsized titanium/niobium carbides that were observed in the microstructure of the weld.

\begin{tabular}{|l|l|l|l|}
\hline Sample State & Region of Interest & Partially Mixed Zone size, $\mu \mathrm{m}$ & White Layer size, $\mu \mathrm{m}$ \\
\hline \multirow{5}{*}{ as-welded } & AW1-L & 43 & $20-23$ \\
\cline { 2 - 4 } & AW1-S & 23 & $9-15$ \\
\cline { 2 - 5 } & AW2-L & 50 & $20-25$ \\
\cline { 2 - 5 } & AW2-S & 34 & $10-15$ \\
\hline \multirow{5}{*}{ PWHT } & PWHT1-L & 48 & $20-27$ \\
\cline { 2 - 5 } & PWHT1-S & 32 & $10-17$ \\
\cline { 2 - 4 } & PWHT2-L & 48 & $3-10$ \\
\cline { 2 - 4 } & PWHT2-S & 24 & \\
\hline
\end{tabular}

Table 2 Main characteristics of the selected ROIs resulting from the mixing of the low-alloy steel and filler metal during welding

\subsubsection{PWHT}

Carbon profiles measured in PWHT samples PWHT1 and PWHT2 are presented in Fig. 5. It can be seen that after PWHT the carbon profiles change little on the LAS side. The data in the decarburized zone seem less spread, suggesting that the carbides present after welding are dissolving. On the weld side, however, it can be noted that a carbon peak is systematically present within the first ten microns. Content values at the peak vary significantly from one location to another, from $0.25 \mathrm{wt}$ \% C for PWHT1-L and PWHT2-L to over $0.6 \mathrm{wt} \% \mathrm{C}$ for PWHT2-S. Past the peak, carbon concentration decreases back to non-detectable contents between 30 and $40 \mu \mathrm{m}$ away from the interface. The local large fluctuations owed to coarse titanium/niobium carbides already seen in the as-welded samples are still present. 


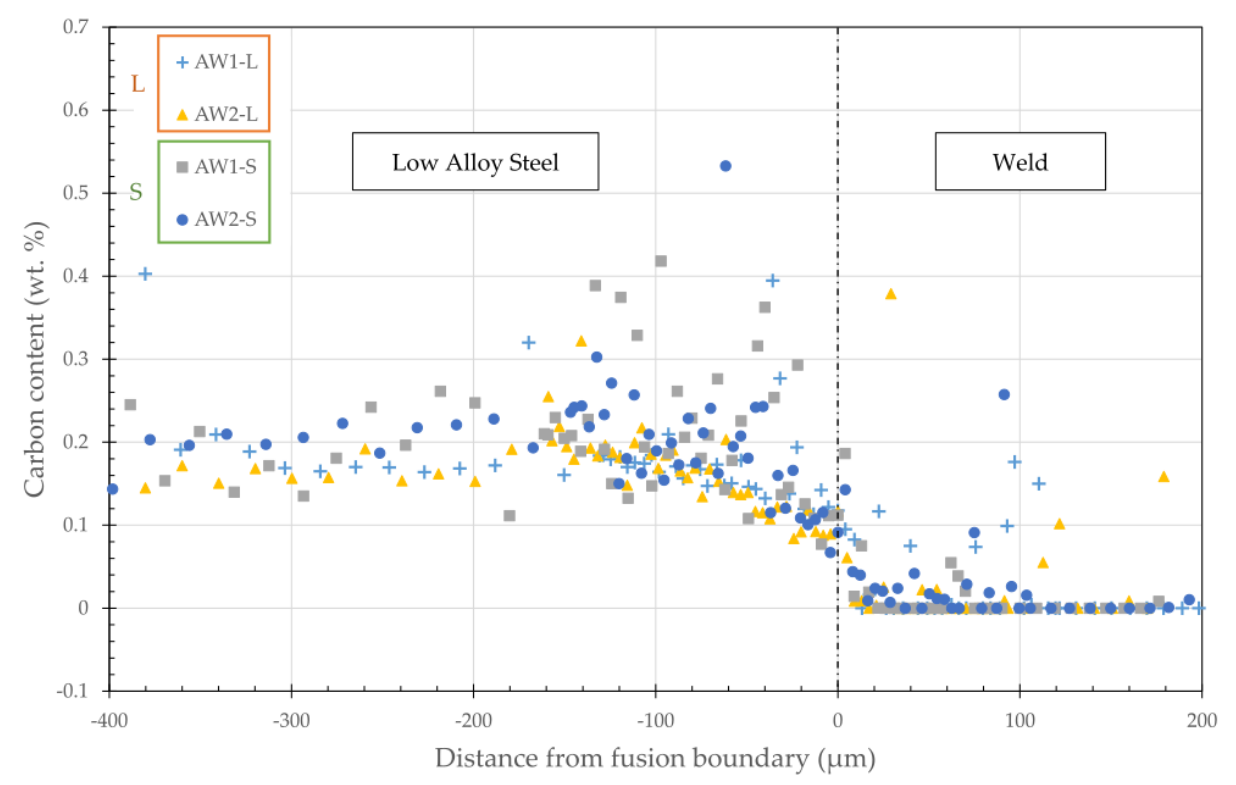

Fig. 4 Carbon composition profiles recorded across the fusion boundary at multiple locations in as-welded samples AW1 and AW2. The overall shapes of all profiles are very similar. Locations noted L (large) feature a partially mixed zone ranging from $43 \mu \mathrm{m}$ to $50 \mu \mathrm{m}$ in size, while those noted S (small) present a partially mixed zone between $23 \mu \mathrm{m}$ and $34 \mu \mathrm{m}$ wide

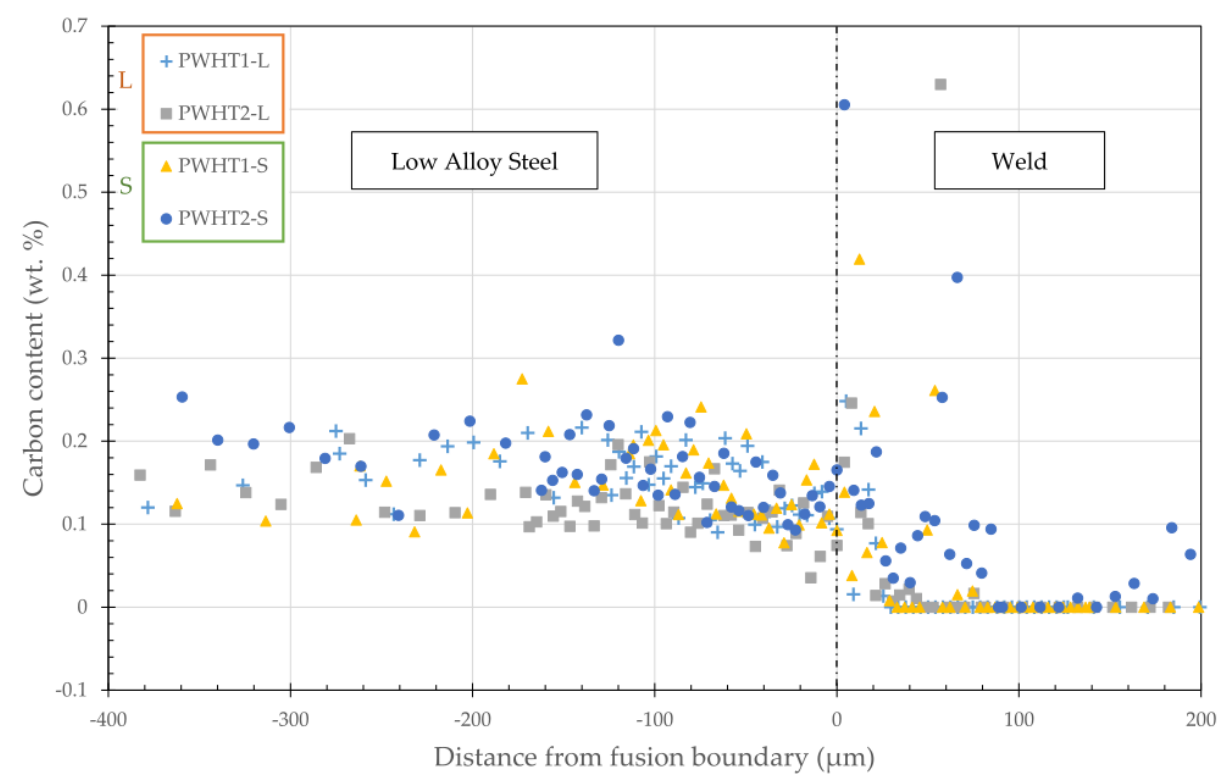

Fig. 5 Carbon composition profiles recorded across the fusion boundary at multiple locations in post-weld heattreated samples PWHT1 and PWHT2. Locations noted L (large) feature a $43 \mu \mathrm{m}$-wide partially mixed zone, while those noted $S$ (small) present a partially mixed zone between $24 \mu \mathrm{m}$ and $32 \mu \mathrm{m}$ wide

\subsection{Microstructural evolution}

An overview of the microstructures of the welds before and after PWHT is presented in Fig. 6, which also shows the locations of the ROIs used for EPMA and nanohardness measurements. It can be seen that the welds present the usual aspect of NG GTAW weld where individual passes can be identified by the periodic change of the white layer directly adjacent to the fusion boundary from a thin parallel-sided layer to a feathery feature, reaching deep into the weld side. 
This layer, unaffected by electro-chromic etching, is a marker of the Fe-rich (> $20 \mathrm{wt} \%)$ region of the weld. Its shape and appearance reveal the local mixing of LAS and filler metal during welding, as shown in Fig. 3. On the weld side, the solidification microstructure right at the fusion boundary is shown in Fig. 7: the planar liquid-solid interface that develops along the interface with the low alloy steel is destabilized after a few $(>10)$ micrometers and replaced by cells and cellular dendrites. Type-I grain boundaries formed during growth as well as migrated grain boundaries are observed in the weld, whereas Type-II grain boundaries, as seen in the upper right corner of Fig. 7, are found very seldom. All those general features are unaffected by the PWHT.
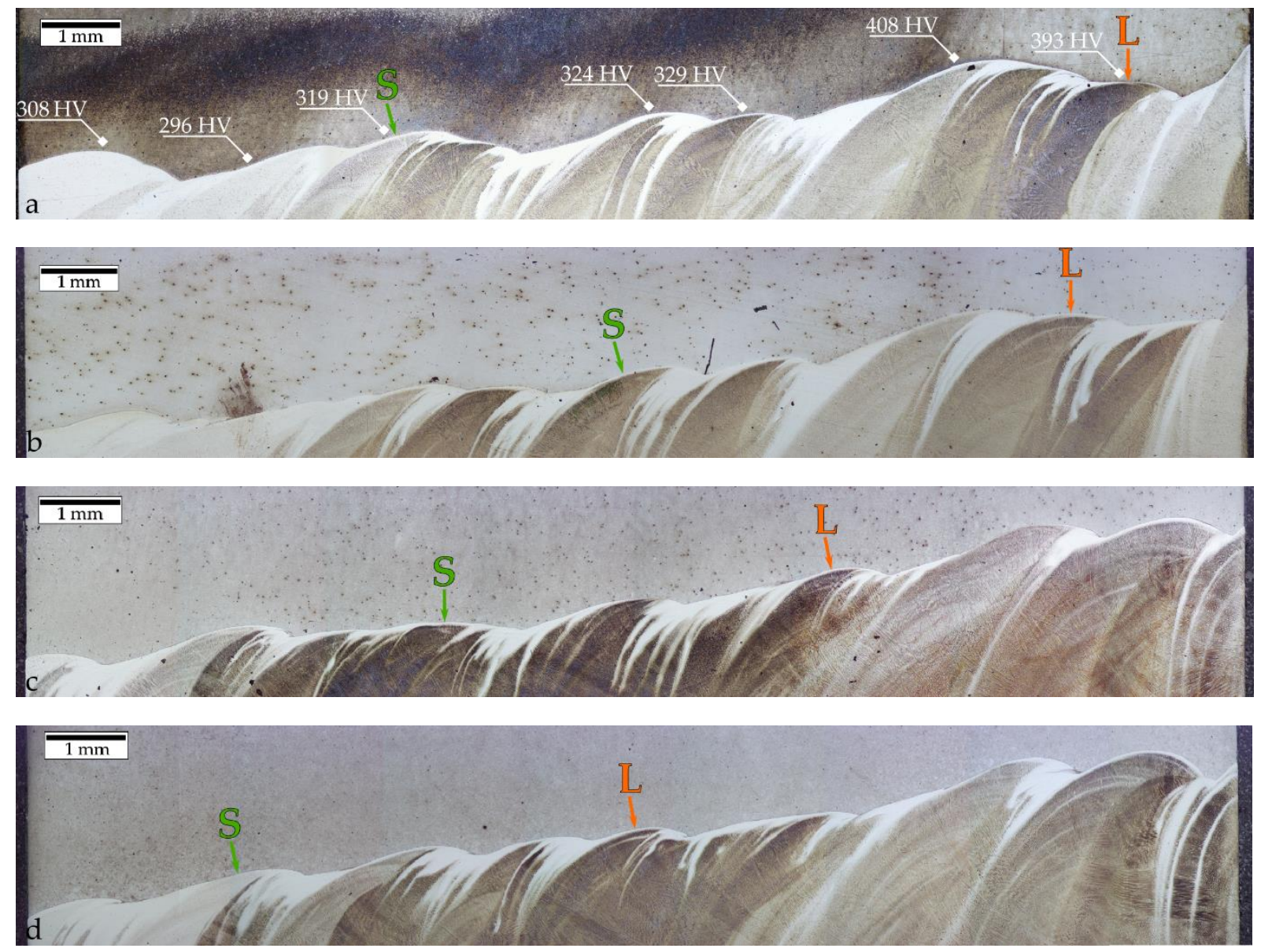

Fig. 6 Light micrographs of samples a) AW1 and b) AW2 in the as-welded condition, and samples c) PWHT1 and d) PWHT2 in the post-weld heat-treated condition. Regions of interest used for finer characterizations of the near fusion boundary area are labeled here, $\mathrm{L}$ in orange for regions with large partially mixed zones and $\mathrm{S}$ in green for small partially mixed zones. The weld passes shown in those micrographs were stacked from left to right. It should be noted that all $\mathrm{S}$ passes are all located lower in the bead stack than L passes. Micro-hardness measurements are also indicated in a) for sample AW1 and were recorded using a $50 \mathrm{~g}$ load, $150 \mu \mathrm{m}$ away from the fusion boundary

\subsubsection{As-welded}

The microstructure of the weld right at the fusion boundary is shown in Fig. 8. On the LAS side, the observed microstructure is made of fine units of a BCC phase containing abundant dislocations and is thus consistent with fresh martensite expected to form during welding. The overlaid EDS signal permits to assess the shape of the composition gradient of the main substitutional elements. The abrupt change in slope suggests a change in mass transport 
mechanism, from convection in the liquid to solid state diffusion. Thus, the exact position the fusion boundary can be inferred from the composition profile. The grains seem finer in a layer about $300 \mathrm{~nm}$ thick directly adjacent to the fusion boundary. The EDS signal reveals that there is a slight diffusion gradient on the LAS side, which extends over about the same distance. A thin layer of martensite can also be seen on the weld side, about $200 \mathrm{~nm}$ thick. Further, a single austenitic grain can be observed, containing numerous fine precipitates. Their appearance is cuboidal or parallelepipedal with a side length ranging from about $15 \mathrm{~nm}$ up to about $100 \mathrm{~nm}$, as can be seen in the higher magnification micrograph in Fig. 9a. From the associated EDS map in Fig. 9b, it can be noted that those precipitates are Fe and Ni depleted while they are strongly enriched in $\mathrm{Nb}$ and $\mathrm{Ti}$. EDS point analyses also revealed that they are enriched in Mo. Those three elements are strong carbide formers. The selected area electron diffraction (SAED) pattern given by the area in Fig. 9a can be seen in Fig. 9c. The brightest reflections seen on the pattern are associated to the face centered cubic (FCC) matrix in [011] zone axis with a lattice parameter of about 3.6 $\AA$. Much dimmer reflections can also be seen and correspond to an FCC structure with a lattice parameter of about $4.4 \AA$, both matching either $\mathrm{NbC}$ or TiC, in a cubecube orientation relationship (OR) with the matrix. It can thus be assumed those precipitates are mixed niobium/titanium $(\mathrm{Ti}, \mathrm{Nb}) \mathrm{C}$ carbides, where part of the metallic atoms are substituted by molybdenum [21, 22].

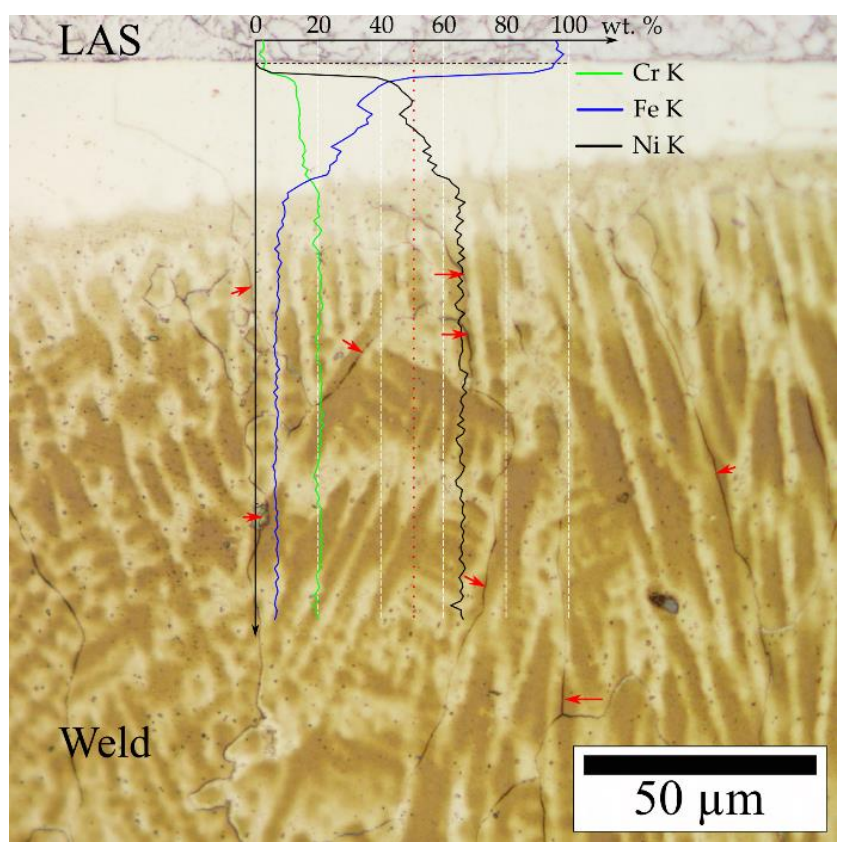

Fig. 7 Light micrograph of the fusion boundary in the as-welded condition (sample AW2) with overlaid EDS profiles for $\mathrm{Fe}, \mathrm{Ni}$ and $\mathrm{Cr}$, recorded on the trajectory indicated by red dots. Solidification microstructures in the weld are evidenced by chromic acid electro-etching. Red arrows highlight migrated grain boundaries 


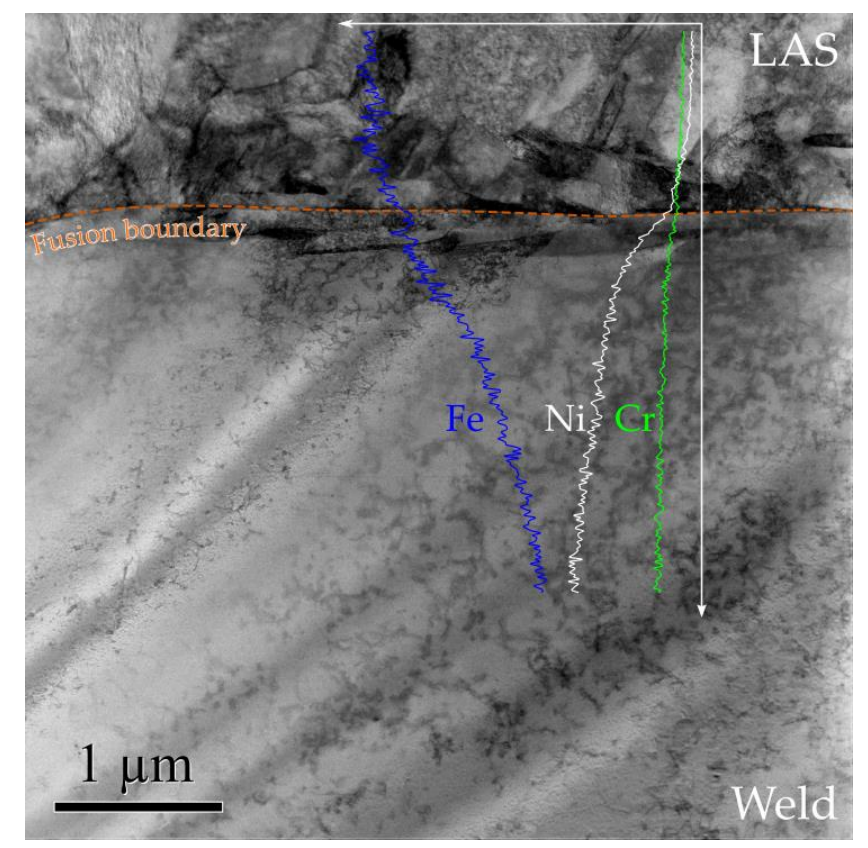

Fig. 8 Bright field STEM micrograph of the fusion boundary in region L of as-welded sample AW1. The overlaid graph shows the evolution of the EDS signal associated to $\mathrm{Fe}, \mathrm{Ni}$ and $\mathrm{Cr}$. The evolution of the composition permits a clear identification of the position of the fusion boundary

\subsubsection{PWHT}

The microstructure around the fusion boundary can be seen in Fig. 10a, and two main changes can be noted. The first is the population of rather coarse precipitates appearing at the fusion boundary and at lath boundaries on the LAS side.

SEM observations suggest they are present in the as-welded state too but at a number density sufficiently lower that they are not found in Fig. 8. As was previously observed [13], subsequent heat treatment, such as PWHT, leads to a sharp increase of their number density, which made it more likely for them to be found in the TEM specimen of Fig. 10a.

The crystal structure of these precipitates was found to match $\mathrm{M}_{23} \mathrm{C}_{6}$ based on electron diffraction. They were also found to be $\mathrm{Cr}$-enriched. All those precipitates were observed to be located at tempered martensite lath boundaries, including the ones at the fusion boundary due to the thin martensite layer present on the weld side that was also seen in the as-welded state.

A large fraction of nano-sized particles can also be seen precipitating intragranularly on the weld side, a few hundreds of nanometers away from the interface. The diffraction pattern in $[001]_{\gamma}$ zone axis seen in Fig. 10b indicates the presence of an FCC phase in cube-cube OR with a lattice parameter about three times that of the matrix, corresponding to $\mathrm{M}_{23} \mathrm{C}_{6}$. It still shows reflections associated to $(\mathrm{Ti}, \mathrm{Nb}) \mathrm{C}$ as well. 

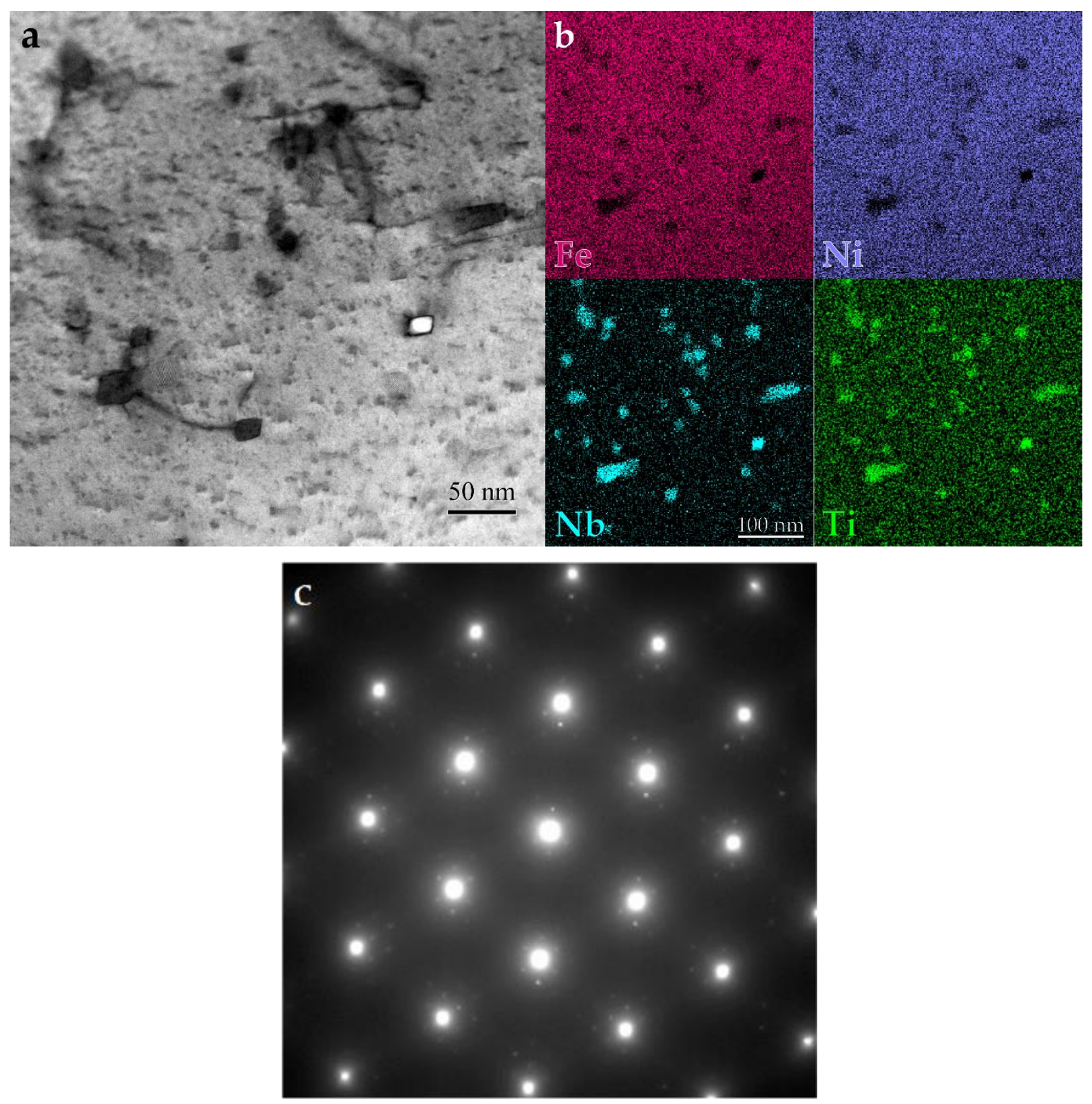

Fig. 9 a) Bright field STEM micrograph of the weld metal near the fusion boundary in region L of sample AW1. b) EDS maps for $\mathrm{Fe}, \mathrm{Ni}, \mathrm{Nb}$ and $\mathrm{Ti}$. Each map presents the distribution of the corresponding element in the whole area shown in a). c) Selected area electron diffraction pattern recorded from region shown in a). It shows the characteristic pattern of the FCC matrix in [011] zone axis. Dimmer reflections indicate the presence of another FCC phase in cube-cube orientation relationship, corresponding to $(\mathrm{Ti}, \mathrm{Nb}) \mathrm{C}$. Reflections corresponding to matrix/precipitate double diffraction events are also visible 


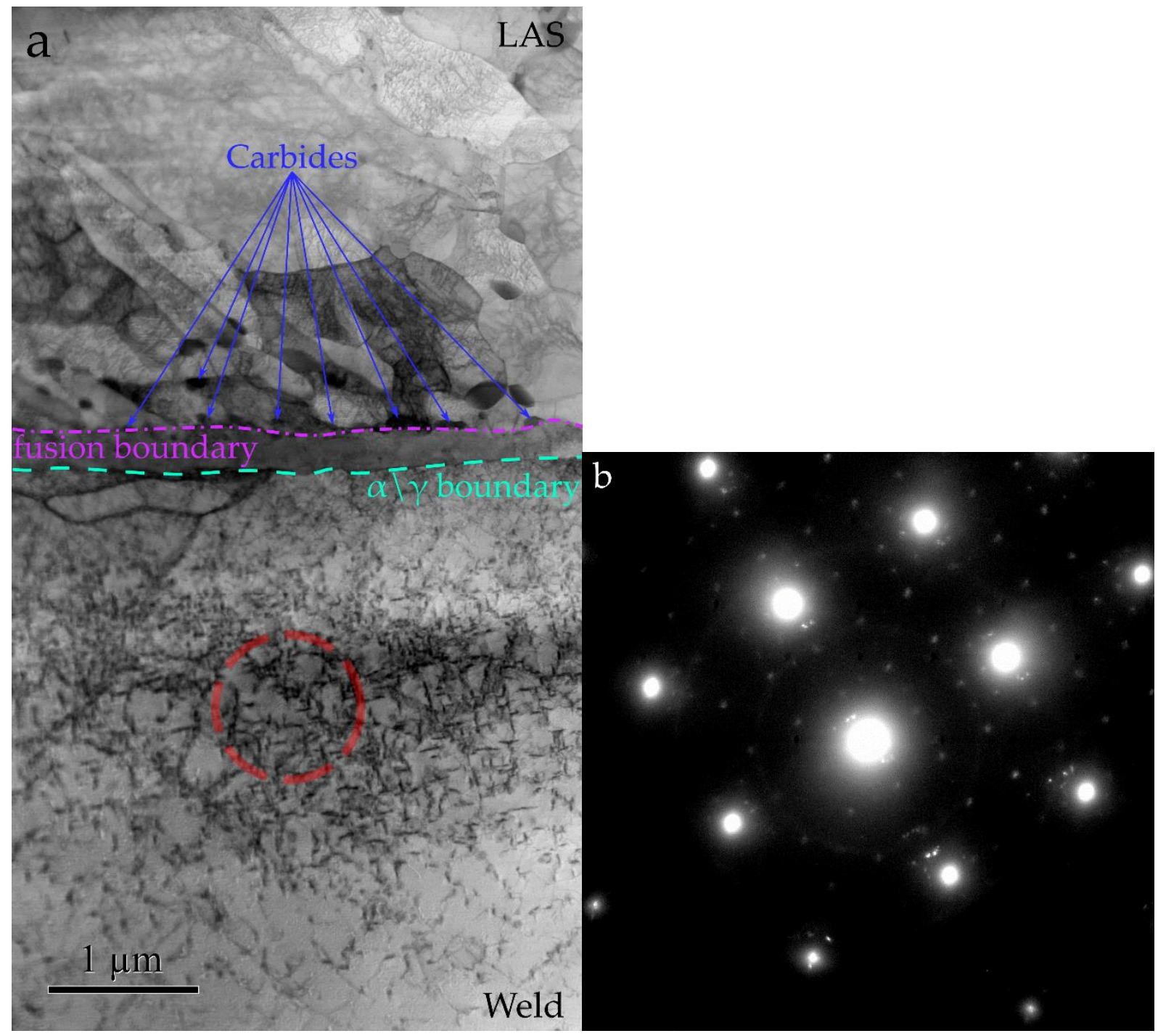

Fig. 10 a) BF STEM micrograph in region L of sample PWHT1. Carbides can be seen on lath boundaries on the LAS side and on the fusion boundary. A thin layer of martensite comparable to the as welded case can be seen on the weld side. However, numerous precipitates, previously absent, can be seen with their peak number density about $2 \mu \mathrm{m}$ away from the fusion boundary. b) Selected area diffraction pattern from the precipitate rich area highlighted by the dashed red circle in a) on the weld side in $\left[001_{\gamma \gamma}\right.$ zone axis. It displays reflections characteristic of both (Ti,Nb)C and $\mathrm{M}_{23} \mathrm{C}_{6}$, in addition to the ones of the austenitic matrix

\subsection{Mechanical properties}

As covered in the previous sections, changes in the microstructure of the weld can occur over short length scale. In order to assess the evolution of the mechanical properties, nanoindentation hardness testing was employed to obtain measurements at coarse $(20 \mu \mathrm{m}$ matrix pitch over $600 \mu \mathrm{m})$ and fine spatial resolutions $(2 \mu \mathrm{m}$ matrix pitch over $40 \mu \mathrm{m})$ across the fusion boundary. The distance of individual indents from the fusion boundary is obtained by highresolution optical imaging. The LAS is positioned on the left side (negative distance from the origin being the fusion boundary). Hardness values are reported at two different depths, $370 \mathrm{~nm}$ and $110 \mathrm{~nm}$ for coarse and fine matrices respectively. Since hardness was found to be depthdependent, only relative changes between various locations and metallurgical states are commented. 


\section{As-welded}

Fig. 11 shows the hardness profiles for the two as-welded samples in their identified ROIs. The measurements reveal important hardness variations depending on the position of the bead in the stack. Accordingly, the reference and coarse measurements far from the fusion boundary show that the LAS displays a pronounced mechanical softening, evolving from $6.2 \mathrm{GPa}$ in average next to the top beads (AW1 P1, AW2 P1) down to 4 GPa for lower ones (AW1 P4, AW2 P2). In comparison, the hardness of the weld metal changes little bead to bead and remains between 4 and $4.5 \mathrm{GPa}$.

The fine measurements provide a higher spatial resolution around the fusion boundary although the values reported can be slightly higher due to the indentation size effect [23]. They show the formation of a hardness peak right at the fusion boundary, which is more pronounced as the considered bead is positioned lower in the stack. This peak is followed in the weld by a positive hardness gradient in the region corresponding to the PMZ. This gradient is similar in all passes.

\section{PWHT}

Fig. 12 reports the hardness profiles of the two PWHT samples, PWHT1 and PWHT2. Reference matrices far from the fusion boundary reveal that the LAS component is softened to hardness values lower than the ones of the weld metal, which is observed to remain in the same range of values as the as-welded state, between 4 and $4.5 \mathrm{GPa}$. The profiles exhibit reproducible shapes. The LAS side exhibits an almost flat hardness profile. Past the fusion boundary, hardness rapidly increases to a maximum that is reached within 4 to $12 \mu \mathrm{m}$ from the interface. Beyond it decreases over a short distance $(20-30 \mu \mathrm{m})$ from this maximum value down to its reference level.

Finally, the data from the mechanical testing of all samples can be gathered on a so called 'phase map' [24]: statistics of Hardness and Elastic modulus (H,E) measurements form clusters that uniquely identify a given composition associated with its microstructure. This representation is shown in Fig. 13, reporting only the coarse matrix $(\mathrm{H}, \mathrm{E})$ measurements for clarity's sake. It can be seen that the LAS hardness increases with the depth in the stack of the neighboring bead in the as welded state, at almost constant elastic modulus. After PWHT, further softening is observed but the dependence on depth in stack is no longer statistically distinguishable. On the other hand, the properties of the weld side evolves only marginally. The deeper beads seem to be statistically slightly harder than the shallower beads in the as-welded state. After PWHT, the hardness is intermediate between those two values. Given the dispersion of the measurements, these differences do not seem to be related to the thermal budget but rather to the inhomogeneity of the material. 

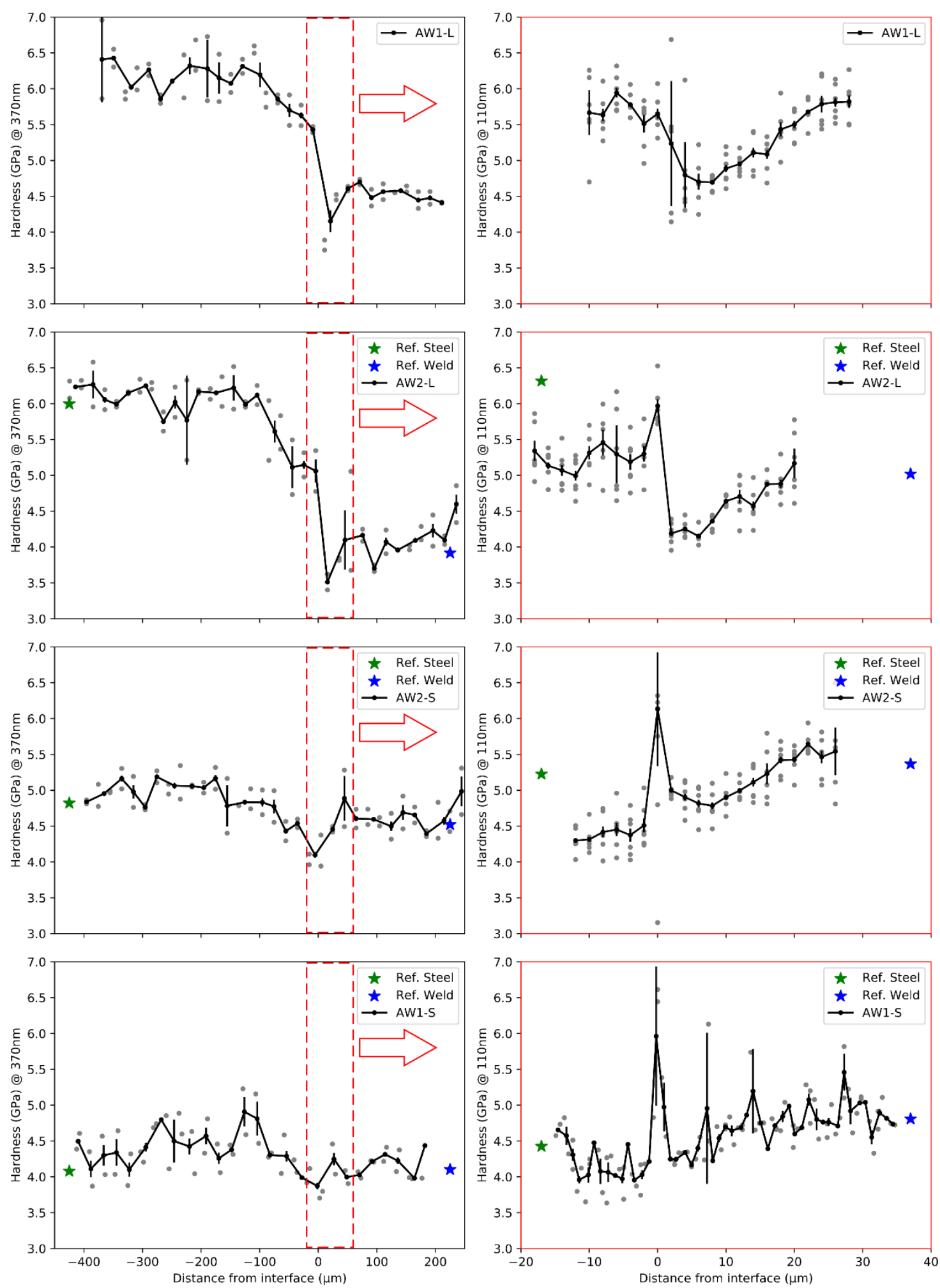

Fig. 11 Nano-hardness profiles for the two as-welded samples AW1 and AW2. The left side column shows coarse matrix measurements ( $370 \mathrm{~nm}$ deep), while the right side one reports the fine matrix measurements (110 $\mathrm{nm}$ deep), closely arranged around the fusion boundary. The section covered by the fine profile is highlighted on the coarse profile with a red dashed rectangle. Data is shown according to the position of the regions of interest in the bead stack, from top to bottom (AW1-L, AW2-L, AW2-S, AW1-S) 

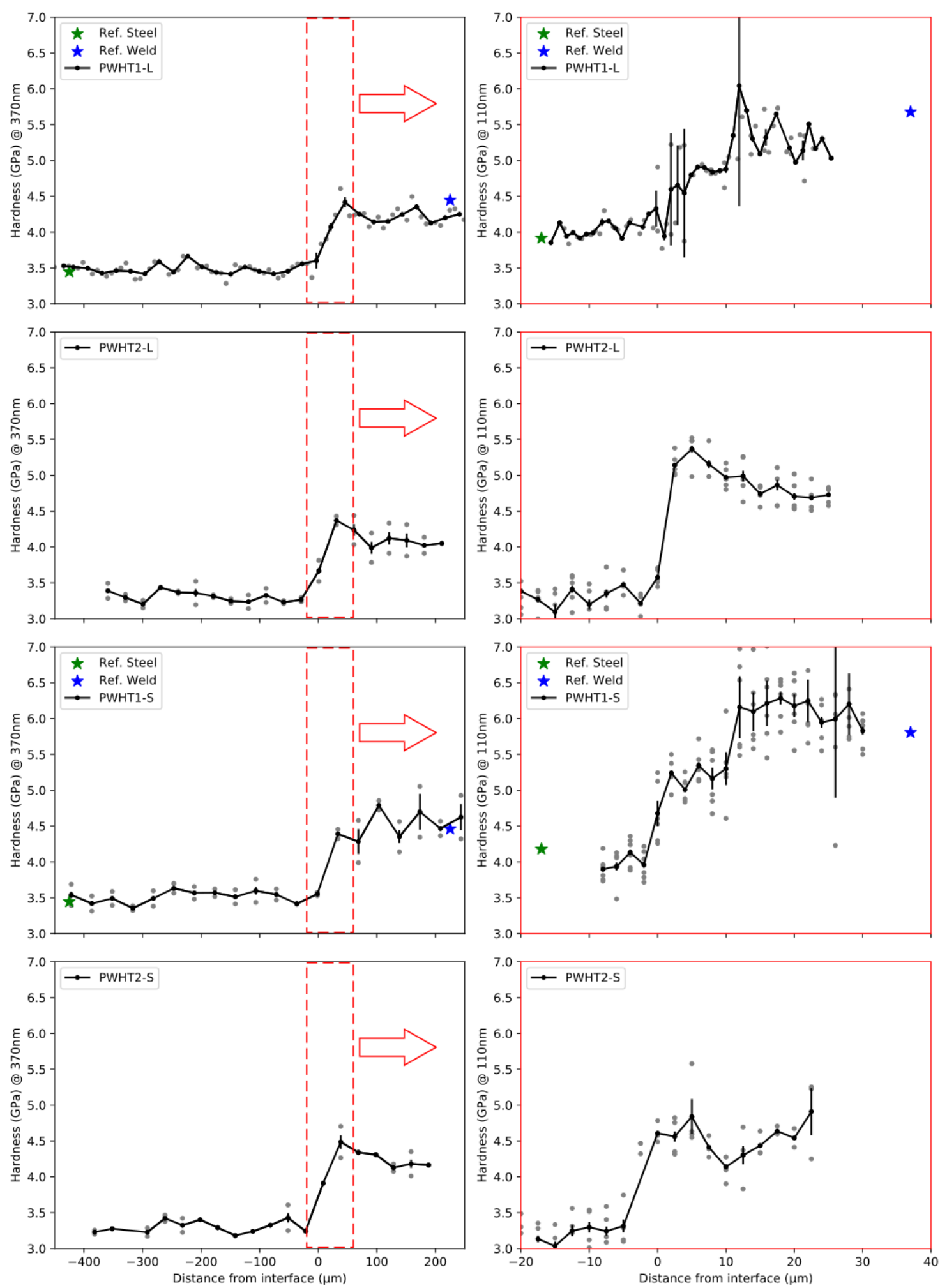

Fig. 12 Nano-hardness profiles for the two post-weld heat-treated samples PWHT1 and PWHT2. The left side column shows coarse matrix measurements $(370 \mathrm{~nm}$ deep), while the right side one reports the fine matrix measurements (110 nm deep), closely arranged around the fusion boundary. The section covered by the fine profile is highlighted on the coarse profile with a red dashed rectangle. Data is shown according to the position of the regions of interest in the bead stack, from top to bottom (PWHT 1-L, PWHT2-L, PWHT1-S, PWHT2-S) 


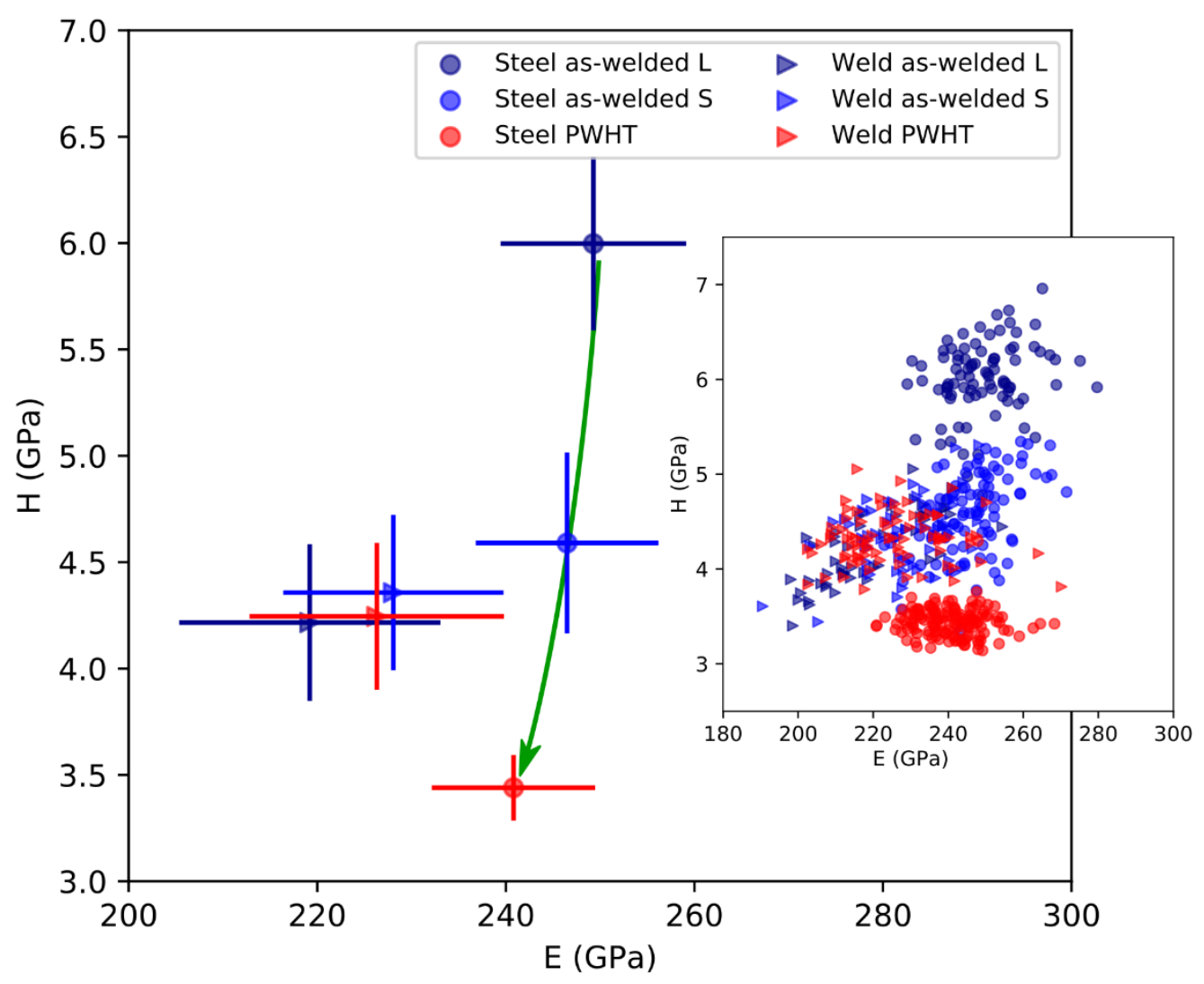

Fig. 13 Mechanical property map summarizing all the $370 \mathrm{~nm}$ measurements (coarse matrices) from all regions of interest in all samples. The error bars represent the standard deviations $( \pm \sigma)$ of each subset. The inset shows the statistical distribution of the data points included in the map. The green arrow shows the trajectory of the properties of the low-alloy steel as its post-weld thermal budget increases

\section{Discussion}

\subsection{ROI selection}

As has already been noted previously in the literature, DMWs produced using NG-GTAW present a very heterogeneous microstructure around the LAS/filler fusion boundary [25]. The fusion boundary evolves from a rather straight continuous line at the top of a bead and becomes a feathery structure that becomes over $100 \mu \mathrm{m}$ wide towards the bottom of the bead. The endeavor of the present paper is to study the effect of PWHT on the microstructure and the properties of the weld. In order to assess what this effect is, it is necessary to ascertain that the observed variations are owed to the PWHT and not simply to local fluctuations inherent to the welding process. To this end, the feathery regions will be disregarded here, notably because they make for a smaller portion of the fusion boundary. In addition, the comparison between ROIs after welding and PWHT was only considered acceptable if both the thickness of the partially mixed zone determined on the EDS composition profiles and that of the white layer measured on optical micrographs were similar. The shape of the composition gradient in the partially mixed zone was assessed using semi-quantitative EDS analysis in SEM in order to rapidly select the ROIs used for EPMA. In all cases, excellent agreement was found between SEM-EDS and EPMA results for substitutional elements. 


\subsection{Importance of bead position in the stack}

Even though NG-GTAW is generally considered a low-heat input technique [11], multiple indications have been found in this study to support an influence of the position of the bead in the stack on the surrounding microstructure and its associated properties. Part of this evidence can be found in the carbon profiles. First, in the as-welded condition, it can be seen that the apparent scatter of the carbon composition data points on the LAS side is maximal against the beads found at the low positions in both samples. Combined with the lower hardness values, this indicates a short range redistribution of carbon in the martensite and the possible formation of carbides. Additionally, the hardness in the as-welded state shows a peak right at the interface whose intensity increases with the depth of the bead. The influence of the position of the bead is also confirmed by micro-hardness measurements where it was found that the hardness of the LAS HAZ increases with the number of the adjoining bead in the as-welded state.

All these observations indicate that the extra thermal input from the overlying beads is sufficient to cause tempering differences on the LAS side and to induce differences in the progress of carbon diffusion. This implies that when comparing fine scale characterization results in different DMWs, the position of the considered bead in the stack matters as well, on top of the various criteria outlined in 4.1 , in particular in the as-welded state.

\subsection{Carbon distribution across the fusion boundary}

In the present DMW, the results shown in Fig. 4 suggest that limited transport of carbon occurs during the welding process even when taking into account the elements in 4.2. Greater amounts of energy, such as the ones encountered during PWHT or in service, are typically required for the activation of carbon diffusion [1].

In the as welded state, there exists a decarburized region as seen in Fig. 4, even though no corresponding enrichment is seen on the weld side. This region of the LAS is heated to a temperature near the fusion point during welding. At this temperature, carbon transport will be extremely fast. The carbon from this region can diffuse to the fusion boundary where the higher chromium lowers its activity. Then, it can transfer to the liquid and distributes in the molten pool, where it would then react with $\mathrm{Nb}$ to precipitate as $\mathrm{NbC}$. At the onset of solidification, it accumulates in the close vicinity of the fusion boundary and precipitates as $\mathrm{M}_{23} \mathrm{C}_{6}$. It could also accumulate in the thin layer of martensite on the weld side. In all cases, it would be concentrated in regions of the microstructure where its total amount would be underestimated in the EPMA profile due to the spatial resolution of the technique.

The presence of the micron-scale coarse NbC carbides is owed to the solidification mechanism. Such precipitates, several tens of micrometers in size, were characterized by SEM-EDS in the intercellular regions of the weld. They are also evidenced by the high local contents recorded on the weld side far from the fusion boundary, in the EPMA profiles in Fig. 4 and Fig. 5. Carbon, both from diffusion and dilution, and niobium accumulate in the liquid ahead of the solidification front leading to high local enrichment between cells where the last remaining liquid is thought to solidify into a mixture of those carbides and austenite. 
Given their size and their homogeneous distribution, the cuboidal nano-scale ( $\mathrm{Ti}, \mathrm{Nb}) \mathrm{C}$ carbides are thought to precipitate from solid state, when the beads are reheated by subsequent passes. The high $\mathrm{Nb}$ content of the filler metal results in an extremely low equilibrium carbon content in the austenitic matrix. For instance, taking a dilution coefficient of about $60 \%$ LAS to represent the first $4 \mu \mathrm{m}$ past the fusion boundary, the equilibrium carbon content is calculated to be $6 \times 10^{-4}$ wt. $\%$ at $900^{\circ} \mathrm{C}$ using the Thermo-Calc 2019a software package with the TCFE9 database.

In the case of ferritic/austenitic DMWs, there exists a driving force for carbon to diffuse from the ferritic LAS to the austenitic weld metal [7]. It can be seen that the PWHT conditions chosen in the present work, $700^{\circ} \mathrm{C}$ for $2 \mathrm{~h}$, lead to an appreciable transfer of carbon and to a simultaneous precipitation of carbides. The carbides that were found to be $\mathrm{M}_{23} \mathrm{C}_{6}$ are consistent with the rapidly increasing chromium content of the weld metal. Once it precipitates into carbides in this steep chromium gradient, carbon is no longer mobile. Combined to its lower mobility in austenite than in ferrite [26, 27], this explains why carbon accumulates over the first $10-15 \mu \mathrm{m}$ on the weld side, albeit up to substantial contents (0.6 wt.\%) as seen in Fig. 5.

\subsection{Effects on the mechanical properties}

The abovementioned changes in the microstructure translate into differences in the local mechanical properties.

In the as-welded state, it can be seen that there exists differences in the hardness profiles along the fusion boundary, as was the case for the carbon profiles. Hundreds of microns away from the fusion boundary, the martensite of the LAS HAZ presents a $370 \mathrm{~nm}$ hardness between about 4.0 and $6.5 \mathrm{GPa}$. The large spread of those hardness values is thought to be related to the inhomogeneities along the fusion boundary inherent to the base metal, the process as well as to the position of the bead in the stack as discussed in 4.2. The hardness of the martensite drops over the last $100 \mu \mathrm{m}$ before the fusion boundary, which is consistent with the observed decarburized zone.

The evolution of the hardness in the weld metal is rather consistent across all passes. The point at the interface can be harder due to the presence of carbide and chromium/carbon enriched martensite. The $110 \mathrm{~nm}$ hardness starts from between 4.0 and $4.5 \mathrm{GPa}$ where it is iron rich (high dilution coefficient) and becomes harder until it reaches the composition of the weld (low dilution coefficient) and a $110 \mathrm{~nm}$ hardness of between 5.0 and 5.5 GPa.

In the as-welded state, it can be seen from the nano-hardness measurement that there exists a strong mechanical contrast between the martensite of the LAS HAZ and the partially mixed zone of the weld, the former being harder than the latter. The soft zone seen in the first $\approx 25 \mu \mathrm{m}$ of the weld can be attributed to the dependence of the austenite mechanical properties on the composition in substitutional elements. This kind of contrast is thought to promote failure in DMWs, where the crack deviates to the lower strength material [10]. The configuration of the mechanical properties seen here is consistent with previous work where plastic deformation localization and crack propagation had been observed to occur in the weld metal in as-welded 2.25Cr-1Mo/alloy $82 \mathrm{NG-DMWs} \mathrm{[2],} \mathrm{although} \mathrm{it} \mathrm{occurred} \mathrm{further} \mathrm{than} \mathrm{the} \mathrm{extent} \mathrm{of} \mathrm{the} \mathrm{present}$ 
soft zone. It is possible that this discrepancy is related to welding parameters, especially filler metal feed rate and heat input [28].

In addition to the stress relief effect, PWHT leads to a tempering of the LAS and allows some of its carbon to transfer to the weld side where the resulting precipitation causes a strong local hardening. In the present PWHT conditions, tempering of this LAS grade is expected to be complete [29]. The $370 \mathrm{~nm}$ values are more even than the as welded condition, between about 3.5 and 4.0 GPa. Even though the decarburization was observed to be similar to the as-welded condition, its effect is no longer visible in the nano-hardness measurements. On the weld side, the carbon enrichment and its associated precipitation reactions are sufficient to level the hardness trough present in the as-welded state and even give rise to a hardness peak in the first $\approx 15 \mu \mathrm{m}$ adjacent to the interface in PWHT L and S. The extent of those effects led here to an inversion of the aforementioned mechanical contrast. This inversed mechanical contrast can be just as detrimental to the fracture resistance of the weld as it has already been observed that specific PWHT could lead to no improvement of the mechanical properties over the as-welded state in a different system [11]. It should be noted that the PWHT used here is in the upper range of usual PWHT for the $2.25 \mathrm{Cr}-1 \mathrm{Mo} /$ alloy 82 combination. Thus, it can be postulated that the present PWHT conditions led to a degree of over-annealing of the DMWs. Samples treated at a lower temperature are currently under investigation to ascertain this hypothesis.

\section{Conclusion}

Multiple characterization techniques were leveraged to establish the effect of a $2 \mathrm{~h} 700^{\circ} \mathrm{C}$ PWHT on the microstructure of the near fusion boundary region in a $2.25 \mathrm{Cr}-1 \mathrm{Mo} /$ alloy 82 DMW. The main results of the study are summarized in Fig. 14.

First, the information acquired at multiple scales highlights the inhomogeneity of the fusion boundary and the importance of careful identification of ROIs for metallurgical studies. It was notably found that the position of the bead in the stack can significantly affect local measures such as hardness or carbon composition profiles across the fusion boundary.

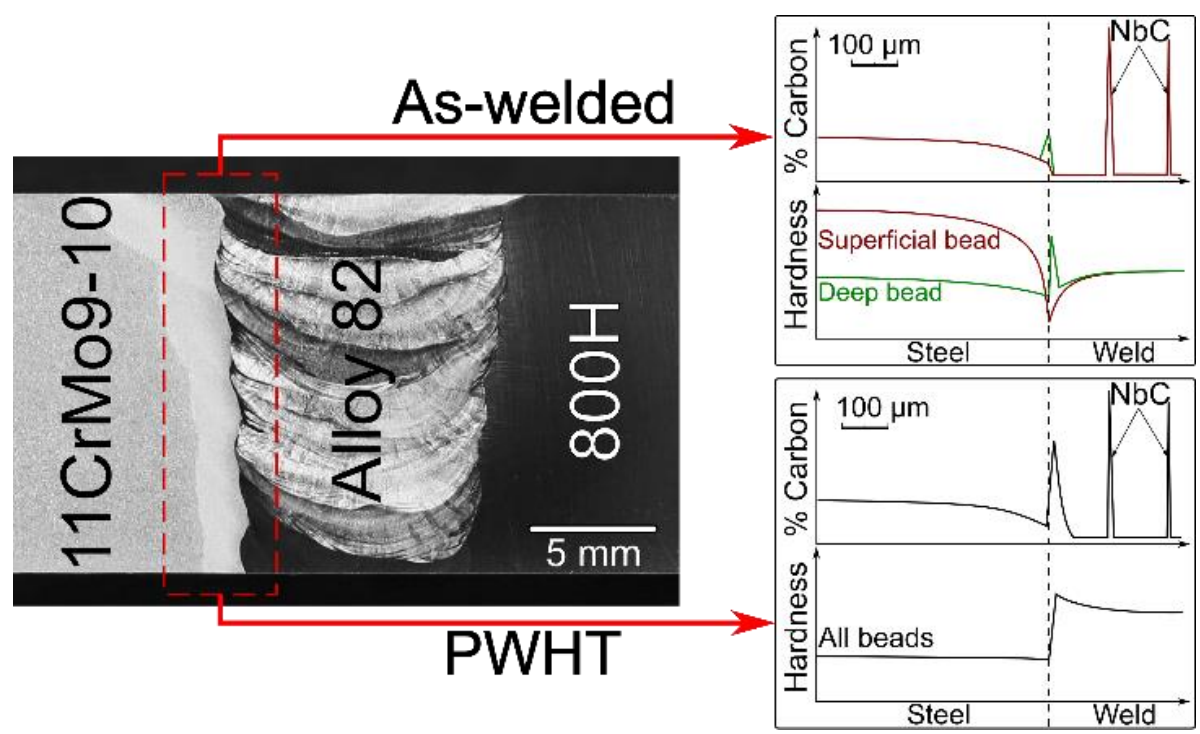

Fig. 14 Synoptic diagram of the characterization results, compared before and after PWHT 
It was observed that the LAS is already decarburized over $\approx 120 \mu \mathrm{m}$ preceding the fusion boundary in the as-welded condition, even though little to no excess carbon is seen on the weld side of the fusion boundary. This carbon is thought to transfer in the liquid during welding and distribute in the bulk of the weld, resulting in low overall elevation of the weld carbon content. Some carbon was also seen to precipitate as micron scale $\mathrm{M}_{23} \mathrm{C}_{6}$ carbides at the fusion boundary. Further on the weld side, two populations of $\mathrm{NbC}$ were found: a coarse micro-scale one and an abundant nano-scale one. As expected, the decarburized region is responsible for a drop in hardness of the HAZ martensite and the presence of the carbides at the fusion boundary causes a hardness peak. Interestingly, it was also found that there exists a hardness trough in the first microns of the partially mixed zone on the weld side, leading to an unwanted mechanical contrast between the hard martensite and soft partially mixed zone.

In addition to complete tempering of the LAS, the present PWHT also caused carbon to solidstate transfer to the weld side, accumulate over about 15 to $20 \mu \mathrm{m}$ past the fusion boundary, and lead to an abundant precipitation of chromium-rich nano-scale $\mathrm{M}_{23} \mathrm{C}_{6}$. This additional carbon transfer is small compared to the amount that has already diffused in the liquid pool, as the decarburized region remained similar. However, it leads to a substantial hardening of the region, compensating the hardness trough seen in the as welded condition and even forming a hardness peak. Combined with the softer martensite, this results in a mechanical contrast, equal but inversed with respect to the as-welded condition. A PWHT at lower temperature might permit to optimize the microstructure to yield a more even hardness profile.

\section{Acknowledgements}

Part of this work was performed with the support of the Center of Excellence of Multifunctional Architectured Materials "CEMAM" No. AN-10-LABX-44-01 funded by the "Investment for the Future" Program overseen by the National Research Agency (ANR).

\section{Author contributions}

C.V. da Silva Lima: Investigation, Visualization. F. Robaut, J. Ghanbaja: Investigation. M. Verdier: Investigation, Visualization, Writing - Review \& Editing. T. Marlaud, G. Badinier: Conceptualization, Resources, Writing - Review \& Editing. C. Tassin: Supervision, Writing Review \& Editing. H.P. Van Landeghem: Supervision, Writing - Original Draft.

\section{Conflict of interest}

The authors declare that they have no conflicts of interest.

\section{References}

1. Brentrup GJ, Dupont JN (2013) Fabrication and Characterization of Graded Transition Joints for Welding Dissimilar Alloys. Weld J 92:72s-79s

2. Nivas R, Singh PK, Das G, Das SK, Kumar S, Mahato B, Sivaprasad K, Ghosh M (2017) A comparative study on microstructure and mechanical properties near interface for dissimilar materials during conventional $\mathrm{V}$-groove and narrow gap welding. J Manuf Process 25:274-283. https://doi.org/10.1016/j.jmapro.2016.12.004 
3. Hänninen H, Aaltonen P, Brederholm A, Ehrnstén U, Gripenberg H, Toivonen A, Pitkänen J, Virkkunen I (2006) Dissimilar metal weld joints and their performance in nuclear power plant and oil refinery conditions. VTT, Helsinki

4. Bitouzet P, Mathieu J, Julien M (1979) SUPERPHENIX - welding of alloy 800 steam generator tubes. British Nuclear Energy Society, United Kingdom, pp 51-54

5. Li GF, Yuan YF, Lu X (2015) Microstructure and Stress Corrosion Cracking of Dissimilar Metal Weld 16MND5/309L/308L/Z2CND18-12N Used for Connecting Reactor Pressure Vessel to Piping in Nuclear Power Plants. Procedia Eng 130:1572-1579. https://doi.org/10.1016/j.proeng.2015.12.327

6. Andresen P (2004) Advanced Testing Techniques to Measure the PWSCC Resistance of Alloy 690 and its Weld Metals. General Electric Global Research Center, Schenectady

7. Brentrup GJ, Snowden BS, Dupont JN, Grenestedt JL (2012) Design Considerations of Graded Transition Joints for Welding Dissimilar Alloys. Weld J 91:252s-259s

8. Martinsson $\AA$ (2006) Ageing influence on nickel-based superalloys at intermediate temperatures $\left(400-600^{\circ} \mathrm{C}\right)$. Luleå University of Technology

9. Marucco A (1995) Phase transformations during long-term ageing of Ni-Fe-Cr alloys in the temperature range $450-600{ }^{\circ} \mathrm{C}$. Mater Sci Eng A 194:225-233. https://doi.org/10.1016/0921-5093(94)09668-6

10. Nevasmaa P, Holmström P, Karjalainen-Roikonen P, Sarikka T, Ahonen M, Mouginot R, Ehrnstén U, Brederholm A, Aaltonen P, Hänninen H (2013) Fracture mechanical characterisation of ferrite-austenite dissimilar metal welds (DMWs) for elevated temperature service in view of metallurgical mis-match. Helsinki-Stockholm, p 23

11. Ahonen M, Mouginot R, Lindqvist S, Sarikka T, Nevasmaa P, Hänninen H (2016) Fracture mechanical and microstructural characterization of narrow-gap safe-end dissimilar metal weld. Helsinki-Stockholm, p 16

12. Laha K, Chandravathi KS, Rao KBS, Mannan SL, Sastry DH (2001) An assessment of creep deformation and fracture behavior of 2.25Cr-1Mo similar and dissimilar weld joints. Metall Mater Trans A 32:115-124. https://doi.org/10.1007/s11661-001-0107-9

13. Parker JD, Stratford GC (2000) Characterisation of microstructures in nickel based transition joints. J Mater Sci 35:4099-4107. https://doi.org/10.1023/A:1004846607046

14. Elrefaey A, Javadi Y, Francis JA, Callaghan MD, Leonard AJ (2018) Evolution of microstructure and toughness in 2.25Cr-1Mo steel welds. Int J Press Vessels Pip 165:20 28. https://doi.org/10.1016/j.ijpvp.2018.05.006

15. Bhaduri AK, Srinivasan G, Gill TPS, Mannan SL (1995) Effect of aging on the microstructure and tensile properties of an alloy 800/9Cr-1Mo steel joint. Int $\mathrm{J}$ Press Vessels Pip 61:25-33. https://doi.org/10.1016/0308-0161(94)P3696-J

16. Coleman K (2007) Guideline for Welding Creep Strength-Enhanced Ferritic Alloys. EPRI, Palo Alto, CA 
17. Hilkes J, Gross V (2013) Welding CrMo steels for power generation and petrochemical applications - past, present and future. Biul Inst Spaw 12

18. Robaut F, Crisci A, Durand-Charre M, Jouanne D (2006) Practical Aspects of Carbon Content Determination in Carburized Steels by EPMA. Microsc Microanal 12:331-334. https://doi.org/10.1017/S1431927606060466

19. DuPont JN (2012) Microstructural evolution and high temperature failure of ferritic to austenitic dissimilar welds. Int Mater Rev 57:208-234. https://doi.org/10.1179/1743280412Y.0000000006

20. DuPont JN, Marder AR (1996) Dilution in single pass arc welds. Metall Mater Trans B 27:481-489. https://doi.org/10.1007/BF02914913

21. Chen CY, Chen CC, Yang JR (2014) Microstructure characterization of nanometer carbides heterogeneous precipitation in $\mathrm{Ti}-\mathrm{Nb}$ and $\mathrm{Ti}-\mathrm{Nb}-\mathrm{Mo}$ steel. Mater Charact 88:69-79. https://doi.org/10.1016/j.matchar.2013.11.016

22. Shanmugam S, Misra RDK, Hartmann J, Jansto SG (2006) Microstructure of high strength niobium-containing pipeline steel. Mater Sci Eng A 441:215-229. https://doi.org/10.1016/j.msea.2006.08.017

23. Milman YuV, Golubenko AA, Dub SN (2011) Indentation size effect in nanohardness. Acta Mater 59:7480-7487. https://doi.org/10.1016/j.actamat.2011.08.027

24. Randall NX, Vandamme M, Ulm F-J (2009) Nanoindentation analysis as a twodimensional tool for mapping the mechanical properties of complex surfaces. J Mater Res 24:679-690. https://doi.org/10.1557/jmr.2009.0149

25. Ahonen M, Lindqvist S, Sarikka T, Mouginot R, Leskelä E, Lydman J, Ehrnstén U, Nevasmaa P, Seppänen T, Arffman P, Hänninen H (2018) Thermal ageing and mechanical performance of narrow-gap dissimilar metal welds. VTT, Tampere

26. da Silva JRG, McLellan RB (1976) Diffusion of carbon and nitrogen in B.C.C. iron. Mater Sci Eng 26:83-87. https://doi.org/10.1016/0025-5416(76)90229-9

27. Bhadeshia HKDH (1981) Diffusion of carbon in austenite. Met Sci 15:477-480. https://doi.org/10.1179/030634581790426525

28. DuPont JN (2010) Review of Dissimilar Metal Welding for the NGNP Helical-Coil Steam Generator. Idaho National Laboratory (INL)

29. Pilling J, Ridley N (1982) Tempering of 2.25 Pct Cr-1 Pct Mo Low Carbon Steels. Metall Trans A 13:557-563. https://doi.org/10.1007/BF02644419 